\title{
Unidades de Conservação e o território no Brasil: estudos de caso em quatro biomas.
}

\author{
Protect Areas and territory in Brazil: cases in four Brazilian \\ biomes.
}

\author{
Alexandre Resende Tofeti ${ }^{1}$ \\ Neio Campos $^{2}$
}

\begin{abstract}
Resumo
Quais são as transformações nos usos do território que uma Unidade de Conservação (UC) promove no Brasil? Essa é a questão instigadora desse artigo. A se considerar que as UCs dos diferentes entes federados perfazem uma considerável extensão do território nacional, essa questão ganha pertinência e complexidade, pois o sistema brasileiro define doze categorias de UCs diferentes com um rol de permissões e proibições distintos para cada uma. Conjuga-se a essa complexidade um território com uma diversidade de situações resultado da sua formação histórica. Selecionou-se em quatro biomas (Mata Atlântica, Cerrado, Caatinga e Amazônia) 20 UCs para estudos de caso, conjugando a realização de entrevistas semiestruturadas com atores chaves e observações de campo ao acionamento das categorias analíticas Formação Socioespacial e Território Usado. À guisa de conclusão, afirma-se nesse artigo que as transformações nos usos do território promovidas pelas UCs são tributárias de quatro variáveis principais: historicidade dos usos do território, adensamento populacional, complementaridade com interesses econômicos e as condições ambientais. A conjugação dessas variáveis em cada território irá condicionar o tipo de transformação dos usos do território que uma UC promove.

Palavras-chaves: Unidades de Conservação. Usos do território. Formação Socioespacial.
\end{abstract}

\begin{abstract}
What are the transformations in the uses of the territory that a Protected Areas (PA) promotes in Brazil? This is the starting point for that article. Considering that the PA of the different federated entities make up a considerable part of the national territory, this question gains relevance and complexity, when one notices that our PA system defines twelve different categories of PA with a distinct set of permissions and prohibitions for each one. This complexity is combined with a territory with a diversity of situations resulting from its historical formation. In order to answer the initial question, we selected in 4 biomes (Atlantic Forest, Cerrado, Caatinga and
\end{abstract}

\footnotetext{
${ }^{1}$ Universidade de Brasília, Departamento de Geografia, Brasília, Distrito Federal, Brasil. xan.tofeti@gmail.com

${ }^{2}$ Universidade de Brasília, Departamento de Geografia, Brasília, Distrito Federal, Brasil. neiocamp@unb.br
} 
Amazon) $20 \mathrm{UC}$ for case studies, conjugating the realization of semistructured interviews with key actors and field observations to the activation of the analytical categories Socio-spatial Formation (Santos, 2005) and Used Territory (Santos, 2007). By way of conclusion, this article states that the transformations in the uses of the territory promoted by the UC are taxed on four main variables: historicity of the uses of the territory, population density, complementarity with economic interests and environmental conditions. The combination of these variables in each territory will condition the type of transformation of the uses of the territory that a PA promotes.

Keywords: Protected Area. Use of the territory. Socio-spatial Formation.

\section{Introdução}

O Brasil é um dos poucos países que atingiu metas internacionais de conservação da biodiversidade, dentre algumas delas a criação de Unidades de Conservação (UCs) revelando uma das faces territoriais mais marcantes da política pública ambiental brasileira. A extensão territorial contempla tanto UCs continentais quanto no ambiente marinho.

Em razão de as UCs apontarem o que pode e não pode ser feito no território e, também, por mobilizarem diversos atores interessados em torno de sua gestão, as UCs transformam concretamente as bases territoriais; em outras palavras, as condições territoriais prévias à criação.

Outrossim, antes de se criar uma UC existia um território ocupado por atores sociais e que, em determinado momento, passam a ter seus usos alterados ou ratificados para atendimento dos preceitos da UC, a depender de seu tipo. Nesse sentido, as UCs geram um rearranjo de forças e ações no território em que se implementam.

Esses rearranjos de forças são muito variáveis a se considerar que o ordenamento jurídico, estabelecido a partir da Lei $\mathrm{n}^{0} 9.985$ (BRASIL, 2000), criou 12 tipos diferentes de UCs agrupadas em duas 
categorias: as de uso restrito, na qual é permitido apenas usos indiretos dos recursos naturais, e as de uso sustentável que preconiza o uso sustentável dos recursos naturais.

A despeito dessa importância, até o momento, não existe estudo sintetizando as transformações que causam na escala de um território nacional. Portanto, esse artigo, procura mostrar quais são as transformações nos usos do território que uma UC promove. Para tanto, apresenta cinco estudos de caso de UCs criadas em relativa contiguidade espacial, para mostrar as transformações nos usos do território causada por elas e fazer uma síntese de como se agregam ao mosaico territorial brasileiro.

\section{Metodologia}

O método adotado nessa investigação considera a materialidade espacial e histórica implicada nos usos do território e suas lógicas específicas.

Só se compreende o conteúdo das formas interpretando o contexto histórico e territorial. Nesse sentido, utilizou-se a categoria Formação Socioespacial, proposta por Santos (2005), que explica o porquê de determinado arranjo territorial existir em determinado Estado-Nação. Por isso, para cada estudo de caso, o foco inicial esteve voltado ao entendimento da história de ocupação do território e seu corolário atual.

Adotamos a técnica de pesquisa de estudos de caso dada a natureza do objeto de análise: um fenômeno social complexo considerando a multiplicidade de interações entre a sociedade e a natureza que as UCs mediam. Yin (2010) afirma que estudos de caso são normalmente adotados para oferecer um entendimento empírico de fenômenos contemporâneos, portanto adequado ao intento de trazer luz 
a uma das facetas da conservação da biodiversidade por meio de UCs, ao desvelar as transformações nos usos do território dessas unidades.

Sendo assim, foi realizada pesquisa de campo ao longo de 4 meses com a realização de entrevistas semiestruturadas, observações de campo, registro visual por filmagem e análise documental de cada grupo de UCs em relativa contiguidade espacial.

O passo primordial foi identificar os principais atores que atuam no território abrangido pela UC e verificar nos discursos dos mesmos quais transformações as UCs promovem em suas vidas diárias ou em suas atividades produtivas.

Cada entrevista constou de sete perguntas que procuraram entender como a UC afetava a vida das pessoas, tanto em termos laborais como no cotidiano. As entrevistas tinham questões específicas para os gestores das UCs e os gestores municipais (em geral secretários de meio ambiente ou de agricultura) considerando sua visão de implementadores de políticas públicas e receptores das UCs no território, respectivamente.

Com relação à seleção dos atores chaves em cada mosaico de UCs, seguiu-se os seguintes critérios: primeira seleção a partir das análises dos documentos de referência das UCs e da composição dos conselhos consultivos e deliberativos. Como estratégia para refinar essa seleção, a primeira entrevista realizada nos territórios era com os gestores federais das UCs que, conhecedores do território e dos atores, indicavam aqueles que mais poderiam ser portadores de um discurso com maior conteúdo à pesquisa. Cabe destacar que os questionários foram desenvolvidos para atendimento da questão de pesquisa sem ênfase em um autor específico, e foram testados previamente à pesquisa de campo, com o secretário de meio ambiente do município de Águas Lindas de Goiás. 
O recorte territorial foi de $20 \mathrm{UCs}$, perfazendo mais de 2,5 milhões de hectares, segundo os seguintes critérios: estarem localizadas em um dos quatro grandes biomas oficiais do Brasil (Amazônia, Caatinga, Cerrado e Mata Atlântica). O entendimento de bioma aqui seguido é o mesmo de Conti e Furlan (2000, p. 138): "comunidade madura ou associações de espécies dominantes numa determinada condição climática vigente".

Do mesmo modo, foram selecionados, em cada bioma, conjuntos de UCs de diferentes categorias com proximidade territorial, para efeito de análise, seguindo o seguinte critério: considerando o mesmo histórico de ocupação do território, a análise de diferentes tipos de UCs oferece a real dimensão do quanto cada uma afeta ou modifica a dinâmica do uso do território. Por isso os biomas Pantanal e Pampas ficaram excluídos da investigação, visto que não existem UCs federais de diferentes categorias próximas territorialmente.

Para esse estudo, não são consideradas as RPPN (Reservas Particulares do Patrimônio Natural) uma vez que: a iniciativa de criação desse tipo de UC provém do proprietário da terra (voluntariamente), e não é contemplado pela gestão do Estado. Acrescenta-se ainda que, a seleção da amostra focou na dinâmica territorial das UCs terrestres. Na Tabela 1 e na figura 1, são apresentados os territórios de análise com as respectivas quantidades de entrevistas. 
Tabela 1: Unidades de Conservação estudadas por Bioma do Brasil.

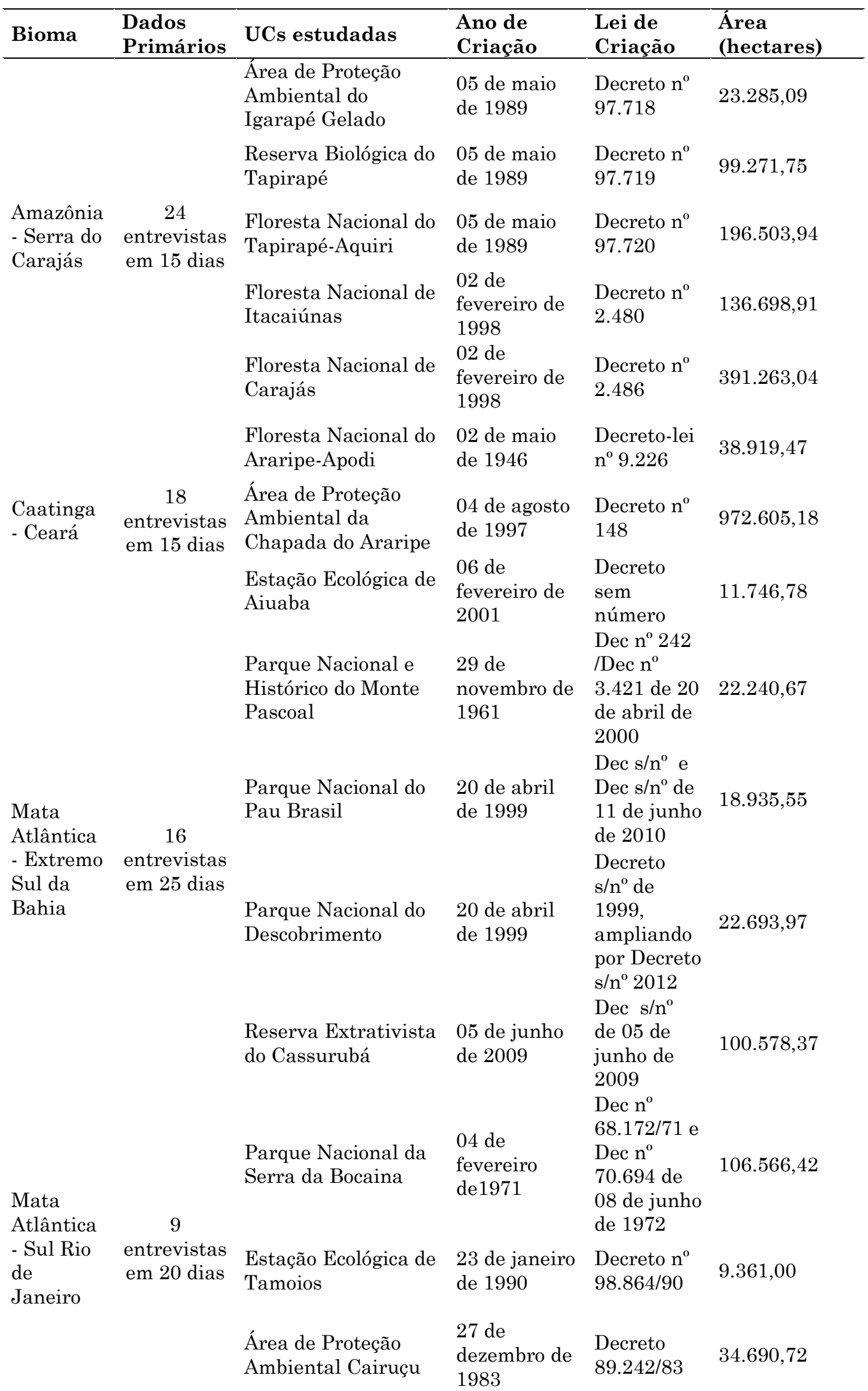




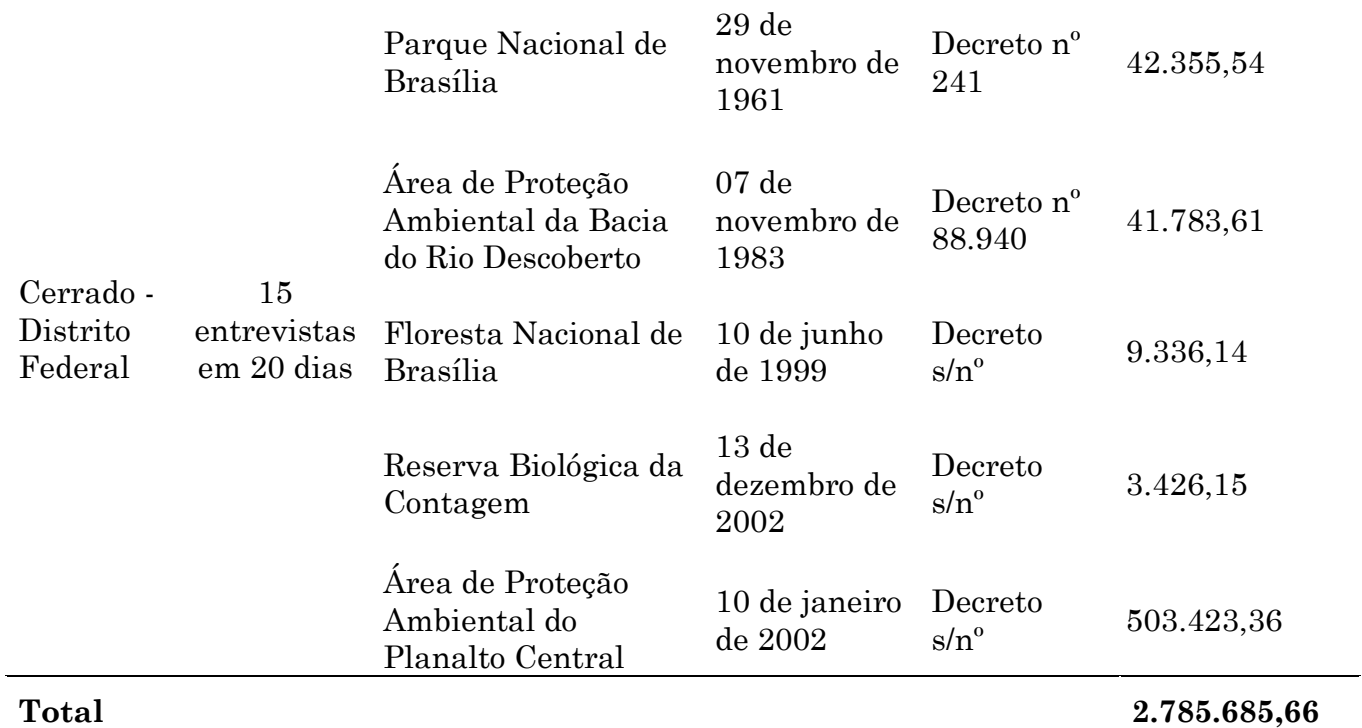

Fonte: ICMBio, 2019, adaptado pelos autores.

As entrevistas foram transcritas para análise manualmente após serem gravadas com gravador digital; para cada grupo de atores (gestores das UCs, gestores federais e atores locais) foram elencadas palavras-chaves a qual houve recorrência nas falas e opiniões, que demonstravam mudanças nos usos do território a partir da criação das UCs, além de permitir compor um entendimento sobre o território visitado e as mudanças nos seus usos. 
Figura 1. Mapa com as UCs estudadas por bioma.

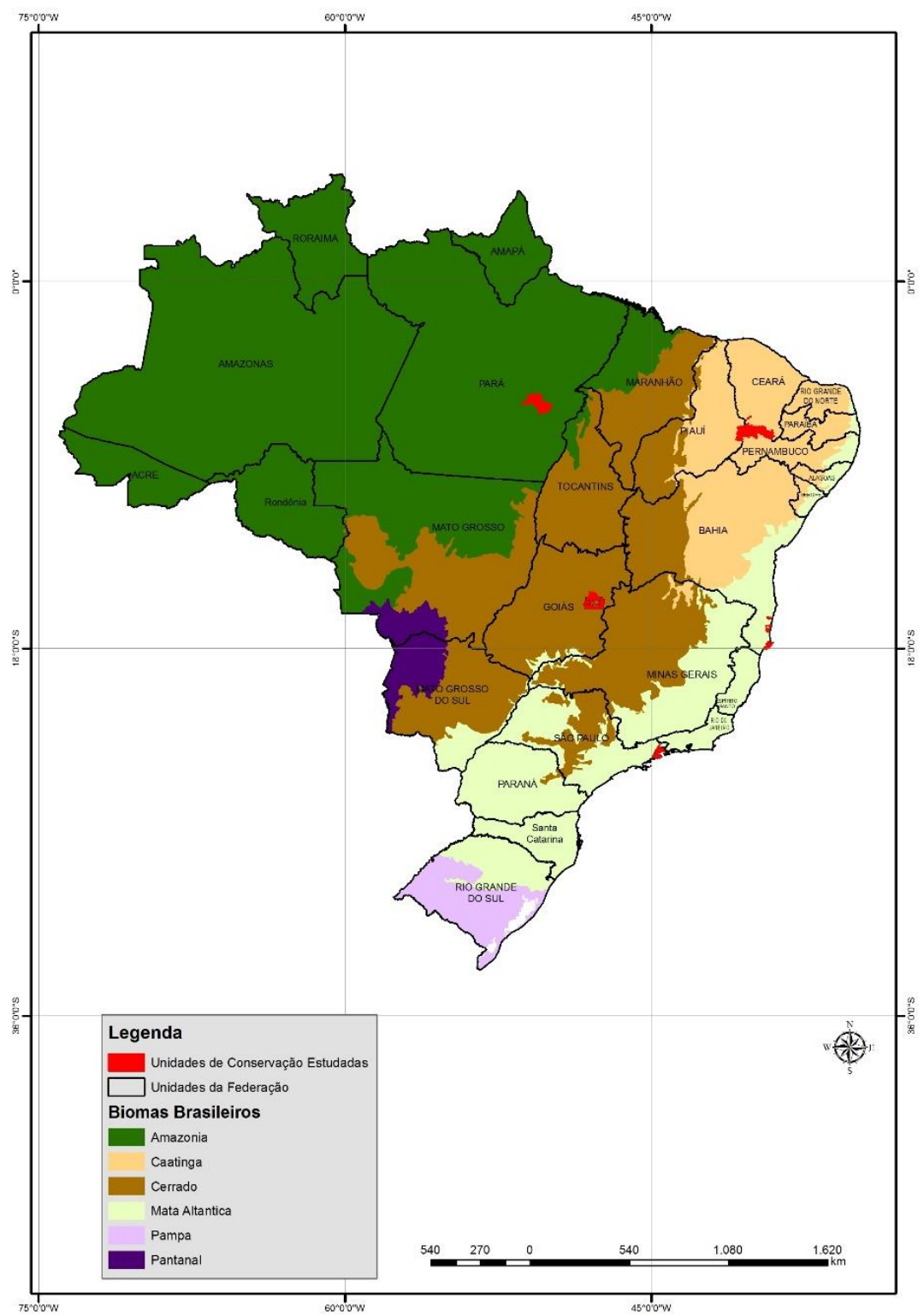

\section{Estudos de caso}

\section{Mosaico de UCs da Serra dos Carajás - PA, bioma Amazônia}

Nesse território de interesse da pesquisa (Serra dos Carajás) é importante destacar três usos do território predominantes: a mineração, a pecuária e a produção rural familiar (assentamentos). 
A extração mineral da Serra dos Carajás tem reflexo em uma boa estrutura de gestão e um apoio institucional diferenciado provido pela empresa Vale às UCs. Segundo os planos de manejo, a criação das primeiras UCs na área atendeu à interesses de controle do território por parte do Estado frente às descobertas das riquezas minerais e às condicionantes ambientais.

A Floresta Nacional (Flona) Itacaúnas é a menos estruturada e regularizada em termos fundiários. Também não é contemplada pelo apoio da Vale. Em contrapartida, a UC com situação mais regularizada em termos de uso e ocupação é a Flona Tapirapé-Aquiri. Não há um conflito de uso estabelecido em seus limites e em seu interior muito em virtude da regularidade fundiária e de estar no centro do mosaico.

A Flona de Carajás também apresenta situação de baixo conflito e regularidade fundiária. A história dessa UC está ligada ainda ao contexto da mineração da Serra dos Carajás. Dentro da Flona existem três usos do território bem delimitados: a mineração, o extrativismo de jaborandi (Pilocarpus jaborandi) e o turismo ambiental, esses dois últimos estimulados após a criação da UC.

Em outro quadrante, a Área de Proteção Ambiental (APA) Igarapé Gelado possui um histórico atrelado às políticas de estímulo à ocupação empreendidas pelo Estado brasileiro. Recebeu parte do espólio populacional da mineração de ouro após a desativação da mina de Serra Pelada; e ainda apresenta em seu território uma represa de rejeitos da mineração.

Por fim, a Reserva Biológica (Rebio) do Tapirapé, mais restritiva, só permite a contemplação, a pesquisa científica e a educação ambiental. Essa UC está classificada como de importância biológica extremamente alta, segundo a Portaria MMA n ${ }^{\circ}$ 9, (BRASIL, 2007). Por se localizar no norte do mosaico está na linha de frente de vetores de 
pressão associados a projetos de assentamento do município de Marabá.

Após a análise das entrevistas e conjugado com a vivência nesse território, foi possível perceber que as UC da Serra dos Carajás representam um caso típico de herança bem-sucedida. Herdaram uma área bem preservada de uma empresa estatal, e, além disso, gozam de condicionantes que as tornam únicas no Brasil. As dimensões presenciadas na área da mineração (maior mina de ferro a céu aberto do mundo) promovem o questionamento sobre a compatibilidade entre a atividade mineradora de alto impacto ambiental e a efetividade de uma UC nessas condições. Trata-se de uma aparente incompatibilidade, visto que há evidências comprovadas de que a efetividade daquelas UC na implementação de práticas ambientais apropriadas é elevada. Também, apoiam políticas de incremento técnico aos agricultores que habitam ao redor das UC e dentro delas, como é o caso da APA. Nesse sentido, conseguiram reduzir tanto as pressões sobre os recursos naturais remanescentes, quanto a utilização de queimadas no preparo do solo.

Uma das consequências imediatas desse contexto territorial é o baixo nível de conflito nas UC pelo fato de haver uma regularidade fundiária. Onde isso não aconteceu o conflito é latente, como é o caso da Flona Itacaiúnas, que foi criada depois e não pertencia a Vale.

Assim, a atuação do Instituto Brasileiro do Meio Ambiente e dos Recursos Naturais Renováveis (Ibama) e, mais recentemente, do Instituto Chico Mendes de Conservação da Biodiversidade (ICMBio) trouxe importantes ações que transformaram alguns usos do território: a atuação para além dos limites das UC foi um diferencial. Ademais, a instituição de usos públicos e extrativismo na Flona Carajás, só aconteceu depois de muita negociação com a empresa Vale. Nesse sentido, é possível afirmar que as UC transformaram os usos do 
território promovendo novos usos e modificando outros por meio de ações no seu entorno, a exceção da Flona Itacaiúnas.

Esse caso demonstra uma perspectiva bem diferente daquela encontrada por Monteiro et al. (2012), no Parque Nacional (Parna) das Sempre-Vivas. Nessa situação última, a gestão foi marcada pelo confronto, dada a visão hegemônica preservacionista no seu ato de criação e pela gestão do território subsequente. Isso tem reflexo na estrutura de governança e participação social: na Serra dos Carajás os Conselhos Deliberativos e Consultivos são ativos e permitem trocas entre a gestão e a população local. No Parna Sempre-Vivas consta-se o contrário.

Em resumo, significa dizer que a maior parte das UCs na Serra dos Carajás são casos exitosos, embora dentro delas ocorram atividades de alto impacto ambiental; o que não invalida sua efetividade em manter muitos hectares de floresta de terra firme da Amazônia e promover uma tentativa de desenvolvimento sustentável ao seu redor.

\section{UC do sul do Ceará - bioma Caatinga}

O território de interesse (sul do Ceará) apresenta três usos preponderantes: urbano, agricultura de subsistência e polo gesseiro demandante de carvão vegetal.

A Estação Ecológica de Aiuaba está localizada na ecorregião da depressão sertaneja, muito suscetível aos processos de desertificação. Essa UC é uma das mais representativas da Caatinga e também a mais desprovida de estrutura de gestão. De toda maneira, sua representatividade ecológica reflete em razoável nível de visitações e pesquisas em andamento.

A Flona Araripe-Apodi foi criada em 1946, sendo a primeira Floresta Nacional criada em território brasileiro (somente a gleba Araripe foi consolidada); e é melhor estruturada se comparada com a 
Estação Ecológica (Esec) Aiuaba. A criação da Flona Araripe-Apodi refletiu preocupações relacionadas ao abastecimento de água de centros urbanos, dada a expansão do aglomerado metropolitano de Crato-Juazeiro do Norte-Barbalha. Atualmente, sofre com a pressão imobiliária relacionada à ocupação por chácaras de lazer da população urbana.

Por último, a APA da Chapada do Araripe abrange uma área de 1.063.000 hectares em três estados diferentes da federação: Ceará, Pernambuco e Piauí, trespassando o território de 33 municípios. Seus limites foram definidos a partir de uma cota altimétrica e, por isso, ganhou as dimensões atuais.

As observações de campo e as entrevistas permitiram perceber que as UC conseguiram transformar os usos dos seus respectivos territórios associados a dois fatores: o gerenciamento de recursos hídricos e o baixo dinamismo econômico rural. Assim, com relação à água, como se trata de um bem natural relativamente escasso na região, o seu relevo e a sua conservação apropriada torna-se claramente tangível para a população.

Dessa forma, fez-se o mote principal para justificar a criação e convencer a população da importância da APA e da Flona. Inclusive o tipo de preservação e usos da Flona fazem-na parecer mais um Parque Nacional do que uma Flona propriamente dita. Com relação ao segundo fator, o baixo dinamismo econômico rural, também fez com que a Esec tivesse sua implementação bem-sucedida e com baixo conflito. Em outro cenário, provavelmente a Esec estaria mais pressionada.

Com relação à $\mathrm{APA}$, ainda há pouca clareza por parte da população sobre seu funcionamento e a sua serventia. Mesmo assim, tem-se conseguido estimular novos usos e impingir características diferenciadas a usos do território históricos, como a coleta do pequi e o uso da lenha. Além disso, a APA tem oportunizado parcerias 
estratégicas aos municípios, fortalecendo sua gestão ambiental e territorial; deixando de ser apenas um enclave federal no território municipal.

Um dos aspectos mais marcantes nesse território está relacionado à existência do Geopark Araripe. Esse Geoparque apresenta uma iconografia mais impactante do que as UCs. Ao longo de todas as vias rodoviárias e dentro dos centros urbanos existe farta sinalização dos geossítios do geoparque.

Em resumo, esse território e suas UCs mostraram aspectos ambientais que são decisivos para aferir a relação entre os propósitos institucionais de uma UC e a legitimação promovida pelas partes interessadas. De fato, podem ser favoráveis ou não nas transformações dos usos do território promovidos pelas UCs. Por isso, o grau de transformação nos usos do território promovido pela Esec e pela APA está condicionado aos aspectos ambientais do território, dado que oferecem limitações aos usos, naturalmente.

Esses casos da Caatinga corroboram com os achados de Laschefski et al. (2012, p. 409): "É o imaginário construído a partir do significado da natureza e da sua função [...] que irá orientar as ações do indivíduo nesse mundo". Segundo os autores, no território de estudo (Minas Gerais), o imaginário construído foi predominantemente de conflito; no caso aqui em estudo, o imaginário foi utilitarista, por isso a maior aceitação das UC por parte da população e seu maior engajamento em sua gestão.

\section{UC no extremo sul da Bahia - Bioma Mata Atlântica}

A Mata Atlântica do sul da Bahia foi relativamente preservada até a segunda metade do século. No entanto, a partir da década de 
1970, a conjuntura socioeconômica propiciou uma mudança de curso em relação à exploração da floresta: extração madeireira intensa, apoiada pelo asfaltamento da BR 101, sucedida pela pecuária. Assim, os principais usos do território em vigor nesse território nos idos de 2017 são pecuária, turismo, monocultura do mamão papaia, silvicultura do eucalípto e assentamentos da reforma agrária.

De modo geral, os parques nacionais dessa porção do território da Bahia se originaram ou por herança de áreas antigas de madeireiras (Parna do Pau Brasil e Parna do Descobrimento) ou para preservar remanescentes de mata atlântica frente as pressões de toda sorte (Parna do Monte Pascoal). Fato é que esse território é permeado de conflitos muito em virtude da especulação imobiliária e de usos históricos de populações indígenas, como os Pataxós, que reivindicam áreas de uso tradicional no Parna do Descobrimento e possuem uma Terra Indígena (Barra Velha) demarcada em sobreposição ao Parna do Monte Pascoal.

Em outro contexto, a Reserva Extrativista (Resex) Cassurubá está localizada no principal complexo estuarino do Banco de Abrolhos. Seus 11 mil hectares de mangues, ilhas e restingas conformam uma das maiores áreas de manguezal da Bahia (NICOLAU, 2014). Além de ser o território de escoamento da silvicultura do eucalipto no sul da Bahia, o fator motivador para a criação da Resex foi a competição por recursos marítimos entre os pescadores e os numerosos marisqueiros de outras localidades; e expectativa de implantação da carcinicultura nesse estuário. Esses dois fatos fizeram com que houvesse mobilização dos pescadores locais para a criação de uma Resex.

A partir das observações de campo e a análise das entrevistas pode-se considerar que o território do sul da Bahia foi um dos mais ricos em termos de diversidade das situações encontradas. Também foi nesse território onde as disputas são mais ferrenhas. O Parna do Pau-brasil 
talvez seja a UC com menos conflitos e que tem promovido um uso público que pode gerar dividendos no futuro com a população local.

A implementação de uso público é o exemplo claro de que trazer a comunidade, ou seja, o agente degradador, para dentro da UC e gerar renda de maneira sustentável tende a apaziguar os conflitos.

A gestão da Resex Cassurubá estava promovendo uma mudança no padrão de relacionamento com os beneficiários a ponto de fomentar novas lideranças e promover questionamentos das antigas que se associaram a uma rede de atravessadores exploradora da classe pesqueira na região. Nesse contexto, as reuniões do conselho da Resex estavam apresentando um quórum elevado e sendo um ambiente de intenso debate.

Diante do exposto, o território da Bahia mostrou que o grau de transformação nos usos do território promovido pelas UC está diretamente relacionado à historicidade dos usos do território e complementaridade com interesses econômicos. Assim, só foi possível criar os Parnas do Pau-Brasil e do Descobrimento porque foram adquiridos de empresas privadas. No entanto, as pressões sofridas pelo Parna do Descobrimento e pelo Parna do Monte Pascoal estão relacionadas à historicidade de usos pretéritos. Por fim, a Resex Cassurubá confirma a historicidade dos usos do território, porém com novos rearranjos de poder no território.

Importante ressaltar nos estudos de caso da Mata Atlântica (Bahia e Rio de Janeiro) a influência do fenômeno da urbanização extensiva destacado por Sancho e De Deus (2015). As UCs desse bioma invariavelmente sofrem influência de grandes e médios centros urbanos concentrados na faixa litorânea, o que resulta em conflitos associados a pressão imobiliária e usos pretéritos. A UC nesse tipo de território tende a rearranjar o quadro de forças ora agindo por comando e controle, ora fomentando o associativismo das comunidades locais. 


\section{UCs no sul do estado do Rio de Janeiro - Bioma Mata Atlântica}

A apropriação dessa parte da Mata Atlântica teve influência de quase todos os ciclos econômicos, principalmente do ouro, diminuindo essa influência com o ciclo do café. Da mesma forma que na Bahia, o asfaltamento da BR 101, ocorrido no final da década de 1970, gerou especulação imobiliária, que, desde então, tornou-se um dos maiores problemas enfrentados pelas UCs nesse território. Por fim, esse território recepcionou a instalação das usinas de Angra dos Reis I e II e de um terminal de construção naval da Petrobrás.

Assim, três fatores confluíram para o atual arranjo de UCs nesse território: especulação imobiliária - APA Cairuçu; área remanescente da Mata Atlântica - Parna da Serra da Bocaina; e usinas nucleares e terminais de construção naval - Esec Tamoios.

A atual conjuntura do Parna é complexa. Parte de sua área está preservada pelo fato de o relevo impossibilitar a ocupação humana. Todavia, as áreas que são passíveis de ocupação sofrem pressão por falta de regularização fundiária. Tal situação ocorre, principalmente, em sua vertente na parte superior da serra. Já a porção no sopé sofre pressão pelo crescimento das cidades, impulsionado pela especulação imobiliária atrelada ao turismo (BRASIL, 2002).

A Estação Ecológica de Tamoios exerce uma função de contenção porque protege, com um raio de um quilômetro, 29 ilhas, ilhotas, lajes e rochedos na baía da Ribeira em Angra dos Reis e na baía da Ilha Grande, em Parati (96,64\% do território da UC é de área marinha e $3,36 \%$ é de área terrestre). Ademais, ela se originou como compensação ambiental pela instalação dos empreendimentos das usinas nucleares (BRASIL, 2006), sendo a UC com melhor infraestrutura de apoio e orçamento. Da mesma maneira, sofre pressão pelo turismo e pela atividade pesqueira. 
Sobre a APA Cairuçu, é possível afirmar que suas complexidades estão atreladas à ocupação por diferentes comunidades: caiçaras, quilombolas e indígenas, além dos condomínios e casas de veranistas. A APA ainda conta com áreas remanescentes de Mata Atlântica bem preservadas devido, principalmente, ao relevo acidentado; e a principal pressão que sofre é a ocupação das encostas e das planícies aluviais em decorrência da especulação imobiliária oriunda do turismo (BRASIL, 2004).

Analisando as entrevistas associadas às percepções em campo, é possível afirmar que esse é um território muito dinâmico por causa do turismo. E essa é uma vocação com suas benesses e problemas. Benesses porque a Mata Atlântica na APA tem retomado áreas que antes eram usadas para a agricultura em virtude dos Caiçaras, agora, usufruírem renda do Turismo de Base Comunitária e adquirem alimentos na cidade utilizando meios mais rápidos (lanchas). No entanto, o turismo também tem ocasionado situações em que o caiçara vende sua casa na beira do mar e começa a ocupar a encosta mais acima.

A percepção sobre o Parna, é de que se manteve como é até hoje única e exclusivamente por causa da geografia acidentada. Onde há ocupação não há o que fazer, pois historicamente a UC foi desprovida de meios para impedir novas ocupações ou mesmo para retirar os ocupantes antigos. A Esec tem se mantido em função da compensação ambiental, apesar de receber pressões de todos os lados.

A situação desse Parna se assemelha com o do Parque Estadual da Pedra Branca, descrito por Iwama et al. (2014). O Parque Estadual carece de regularização fundiária o que tem acarretado pressões de ocupação. Só não ocorreu mais dada sua geografia acidentada. Aliás, a questão fundiária é crônica em várias UCs no Brasil muito em virtude do baixo aparelhamento do Estado para sua gestão. 
Por fim, a APA é uma das UCs mais complexas considerando toda a diversidade cultural que ela abarca e os bons exemplos de ações de empoderamento das comunidades locais, além de estar, em certa medida, contingenciando uma especulação imobiliária forte.

O grau de transformação nos usos do território está diretamente relacionado às seguintes variáveis: a) historicidade dos usos; b) adensamento populacional; c) complementaridade com interesses econômicos; e d) as condições ambientais.

\section{UCs no Distrito Federal e seu entorno - bioma Cerrado}

Brasília está inserida integralmente no Cerrado, território das UCs em estudo nesse bioma. Essa cidade e o território do Distrito Federal sofreu intenso processo de crescimento populacional.

É nesse contexto que, a partir das décadas de 1980 e 1990, surgem as UC para tentar dar uma ordem territorial às ocupações e loteamentos irregulares no DF. À exceção do Parna de Brasília, que foi criado ainda na década de 1960, todas as outras UCs têm como objetivo buscar frear a expansão urbana e proteger mananciais de recursos hídricos no DF. Atualmente, mais de 90\% do território do DF é afetado por algum tipo de UC federal (BRASIL, 2012).

O Parna de Brasília chegou antes de toda a ocupação no DF, e esse fato refletiu em sua condição de baixo conflito fundiário e legitimidade frente à sociedade que o circunda. A atualidade da situação do Parna de Brasília é de consolidação efetiva e usos públicos bem estabelecidos, porém o crescimento da mancha urbana fez surgir várias pressões no seu entorno.

A Rebio da Contagem chegou depois da ocupação com o propósito de conter a expansão urbana. Como essa categoria não precisa de consulta pública, seu rito de criação é mais expedito e foi utilizada essa 
prerrogativa para dar cabo dos problemas advindos da expansão urbana não adequada ao Plano Diretor de Ordenamento Territorial do DF (SHIRAISHI, 2011).

A Flona de Brasília é um caso atípico. Foi criada em quatro glebas não contíguas, em quase sua totalidade, dentro da APA da Bacia do Rio Descoberto, buscando proteger nascentes importantes dessa bacia hidrográfica. A biota que objetiva proteger não é tipicamente do Cerrado, pois esse foi desmatado e se plantou espécies exóticas (Pinus sp. e o Eucaliptus sp.) no afã de tentar conter a expansão imobiliária no final da década de 1970.

Mas o resultado dessas ações governamentais originou uma paisagem insólita pelo fato de as espécies exóticas não terem sofrido manejo adequado. Para completar o quadro sui generis, atualmente a Flona tem sido muito utilizada para lazer por grupos de ciclista, caminhantes e escoteiros, diferente do que é preconizado em lei em termos de objetivos de usos para uma Flona.

A APA do Descoberto foi criada com objetivo de ordenar a ocupação e usos do território da bacia do principal manancial de abastecimento de água do DF, o Lago do Descoberto. Ao longo do tempo também foram criadas dentro da APA (UC distritais e estaduais mais restritivas: Reserva Biológica do Rio Descoberto, Parque Ecológico Veredinha e Parque Estadual do Descoberto (BRASIL, 2014). A APA continua com o desafio de coibir o adensamento populacional e se manter predominantemente rural.

Por último, a APA do Planalto Central é a mais complexa. Abrange um território muito amplo com intenso processo de urbanização. Por isso, tem que fazer a gestão de um território com mais de 500 mil habitantes, 90\% desses estão em área urbana e os outros 10\% em área rural (BRASIL, 2012). Foi criada como reflexo de uma situação territorial de rápido crescimento desordenado e pressões sobre 
remanescente do Cerrado e sobre os recursos hídricos, o que demonstra, novamente, o fracasso do planejamento territorial do DF.

Pela vivência e o discurso dos entrevistados, admite-se que esse território, embora com suas especificidades, é ilustrativo de várias situações que ocorrem no Brasil: a flexibilização de regras em prol da ocupação e grilagem de terra; o fracasso do planejamento territorial; e os conflitos pelo uso do território.

A política de UCs, se não chegou primeiro, vem a reboque do motor da história. No caso de Brasília, devido às proporções que ganhou em termos de habitantes, é difícil imaginar uma UC transformando a vida das pessoas por meio de renda e emprego, ou até geração de oportunidades. Por isso que elas foram lembradas pelos atores locais, majoritariamente, como espaço de lazer.

Mais uma vez se comprovou que UCs prístinas têm grau de sucesso maior em garantir sua incolumidade. Em contrapartida, as outras precisam se adaptar à realidade territorial, pois, do contrário, são desconstituídas; e também têm poucas condições de impor não usos do território. Assim, confirma que as variáveis que condicionam as transformações nos usos do território são: a historicidade dos usos, o adensamento populacional, e as condições ambientais.

$\mathrm{O}$ fato de algumas UCs estarem isoladas no interior de uma malha urbana imensa demonstra que se elas não existissem provavelmente teríamos uma das maiores e mais densas manchas urbanas do país. Isso se aplica, principalmente, para o Parna, a Rebio e a Flona. Para as APAs, talvez os usos fossem similares ao que é hoje, com a ressalva de que, provavelmente, a APA do Rio Descoberto tivesse mais densidade demográfica. 


\section{Considerações Finais}

Afinal, quais são as transformações nos usos do território que uma UC promove? Pelos casos concretos estudados, não existe resposta única. Não é possível vaticinar que as UCs de proteção integral promoveram maiores transformações nos usos do território do que as de uso sustentável. Por isso, ficou claro que o contexto territorial e histórico, os aspectos ambientais, a complementariedade com atividades econômicas e o adensamento populacional são determinantes para o tipo de transformação nos usos do território. Os casos estudados foram ilustrativos e são típicos de várias situações no território brasileiro.

A partir dos estudos de caso, reforça-se alguns achados: UCs com parcerias estabelecidas com atividades econômicas e poluidoras conseguem promover transformações nos usos do território.

Da mesma maneira, UCs que protegem bens tangíveis são mais efetivas na transformação dos usos do território.

Existe um potencial da gestão da UC a partir do perfil do gestor em promover rearranjos nas estruturas de poder estabelecidas no território. Porém, quanto mais diversificados os interesses dentro do território e quanto maior a densidade populacional, mais limitadas serão as chances de implementação de tal proposta.

A pressão imobiliária é uma característica bastante comum a muitas UCs no Brasil.

$\mathrm{O}$ turismo tem um grande potencial tanto para transgredir os regramentos das UCs quanto para garantir sua perpetuidade.

Por todo esse apanhado, pode-se afirmar que as UC investigadas e seus respectivos contextos territoriais demonstram que entre a norma das UCs e a realidade territorial o fator determinante é a complementaridade com o maior número possível de interesses em 
voga. Se a gestão da UC adota esse expediente é provável que, mesmo carente de estrutura administrativa, será possível alcançar os objetivos para as quais foi instituída e afetar ou criar usos do território. Do contrário, as UCs irão influenciar alguns usos e outros não, em graus variados. Fatores como historicidade dos usos do território, adensamento populacional e complementaridade com interesses econômicos e condições ambientais são a medida da complexidade em se estabelecer correlações com diferentes interesses constituídos nos territórios.

\section{Referências}

BRASIL. Lei 9.985 de 18 de julho de 2000. Disponível em: http://www.planalto.gov.br/ccivil_03/leis/L9985.htm. Acessa em: 20 de novembro de 2019.

BRASIL. Instituto Chico Mendes de Conservação da Biodiversidade. Plano de Manejo Parque Nacional da Serra da Bocaina. Brasília: ICMBio, 2002. Disponível em: <http://www.icmbio.gov.br/parnaserradabocaina/extras/62-plano-demanejo-e-monitorias.html>. Acesso em: 30 de novembro de 2018.

BRASIL. Instituto Chico Mendes de Conservação da Biodiversidade. Plano de Manejo Área de Proteção Ambiental de Cairuçu. Brasília: ICMBio, 2004. Disponível em: <http://www.icmbio.gov.br/portal/images/stories/plano-demanejo/plano de manejo apa cairucu 2018 2019.pdf>. Acesso em: 10 de outubro de 2018.

BRASIL. Instituto Chico Mendes de Conservação da Biodiversidade. Plano de Manejo Estação Ecológica de Tamoios. Brasília: ICMBio, 2006. Disponível em: $<$ http://www.icmbio.gov.br/esectamoios/destaques/16-plano-de-manejo/48-plano-de-

>. Acesso em: 30 de novembro de 2018.

BRASIL. Ministério do Meio Ambiente. Áreas Prioritárias para conservação, uso sustentável e repartição de benefícios da biodiversidade brasileira. Portaria MMA $\mathrm{N}^{\circ}$. 9, de 23 de janeiro de 2007. Disponível em: < https://www.mma.gov.br/estruturas/chm/_arquivos/biodiversidade31.pdf $>$. Acesso em: 20 de novembro de 2019.

BRASIL. Instituto Chico Mendes de Conservação da Biodiversidade. Plano de Manejo Área de Proteção Ambiental do Planalto Central. Brasília: ICMBio, $2012 . \quad$ Disponível

em:

$<$ http://www.icmbio.gov.br/portal/unidadesdeconservacao/biomas-

brasileiros/cerrado/unidades-de-conservacao-cerrado/2059-apa-do-planalto-central>. Acesso em: 10 de outubro de 2018.

BRASIL. Instituto Chico Mendes de Conservação da Biodiversidade. Plano de Manejo Área de Proteção Ambiental da Bacia do Rio Descoberto. Brasília: ICMBio, $2014 . \quad$ Disponível em: $<$ http://www.icmbio.gov.br/portal/unidadesdeconservacao/biomas- 
brasileiros/cerrado/unidades-de-conservacao-cerrado/2055-apa-da-bacia-do-riodescoberto>. Acesso em: 10 de outubro de 2018.

CONTI, J. B., FURLAN, S. A. Geoecologia: o clima, os solos e a biota. In: ROSS, J. L. S. Geografia do Brasil. $3^{a}$ ed. São Paulo: Editora da Universidade de São Paulo, 2000.

IWAMA, A. Y.; LIMA, F. B. de; PELLIN, A. Questão fundiária em áreas protegidas: Uma experiência no Parque Estadual da Pedra Branca (PEPB), Rio de Janeiro, Brasil. Sociedade \& Natureza, v.26, n.1, 2014. https://doi.org/10.1590/1982$\underline{451320140106}$

LASCHEFSKI, K. A.; DUTRA, C.; DOULA, S. M. A legislação ambiental como foco de conflitos: uma análise a partir das representações sociais da natureza dos pequenos agricultores em Minas Gerais, Brasil. Sociedade \& Natureza, v.24, n.3, 2012. https://doi.org/10.1590/S1982-45132012000300003

MONTEIRO, F. T.; PEREIRA, D. B.; DEL GAUDIO, R. S. Os(as) apanhadores(as) de flores e o Parque Nacional das Sempre-vivas: entre ideologias e territorialidades. Sociedade \& Natureza, v.24, n.3, 2012. https://doi.org/10.1590/S198245132012000300004

NICOLAU, O. S. Às Margens da Resex do Cassurubá no Banco dos Abrolhos: construções identitárias, práticas culturais e processos de territorialização. Rio de Janeiro: 2014. 227 f. Tese (Doutorado em Antropologia) - Programa de PósGraduação em Antropologia Universidade Federal Fluminense.

SANTOS, M. Da totalidade ao lugar. São Paulo: Edusp, 2005.

SANTOS, M. O espaço do cidadão. São Paulo: Edusp, 2007.

SANCHO, A.; DEUS, J. A. S. de. Áreas protegidas e ambientes urbanos: Novos significados e transformações associados ao fenômeno da urbanização extensiva. Sociedade \& Natureza, v.27, n.2, 19 nov.2015. https://doi.org/10.1590/1982$\underline{451320150203}$

SHIRAISHI, J. C. Conflitos ambientais em Unidades de Conservação: percepções sobre a Reserva Biológica da Contagem. Brasília, 2011. $115 \mathrm{f}$. Dissertação (Mestrado em Desenvolvimento Sustentável) - Centro de Desenvolvimento Sustentável da Universidade de Brasília.

YIN, R. K. Estudo de caso: planejamento e métodos. $4^{a}$ ed. Porto Alegre: Bookman, 2010. 